\title{
$O$ conceito de cogestão em saúde: reflexões sobre a produção de democracia institucional
}

\section{| ${ }^{1}$ Francini Lube Guizardi, ${ }^{2}$ Felipe de Oliveira Lopes Cavalcanti |}

Resumo: Este ensaio tem por objetivo discutir os elementos necessários à composição do conceito de cogestão, tendo por perspectiva a necessidade de repensar os modos de gestão do Sistema Único de Saúde, já que o cotidiano institucional expõe as limitações que a tradição gerencial enfrenta na concretização das políticas públicas que o estruturam, principalmente quando se apresenta como horizonte desejado a transformação democrática de suas instituiçôes. Para tanto, apresentamos o conceito de cogestão formulado por Gastão Wagner Campos e, em seguida, realizamos uma reflexão teórica sobre três elementos específicos, a saber: a noção de porosidade, a produção de novas lógicas de pertencimento institucional e as relações entre cogestão e conhecimento. Por fim, propomos pensar a cogestão como socialização e democratização da constituição de artifícios institucionais, destacando o reconhecimento de sua dependência direta dos fluxos e redes sociais que promovem a socialização dos saberes, dos dispositivos tecnológicos e organizativos. Ao remetermos o conceito de cogestão para o plano da articulação em rede das atividades de produção de saúde, procuramos refletir sobre o desafio de construção de novas sociabilidades democráticas, capazes de concretizar materialmente o direito à saúde. A cogestão das instituições seria, nessa perspectiva, uma dimensão fundamental da coprodução de saúde.

> Palavras-chave: gestão em saúde - democracia - políticas públicas.
1 Psicóloga, doutora em Saúde

Coletiva pelo IMS-UERJ e assistente de pesquisa do Laboratório de Educação Profissional em Gestão em Saúde da Escola Politécnica de Saúde Joaquim Venâncio/ Fiocruz. Endereço eletrônico: flguizardi@hotmail.com

${ }^{2}$ Médico residente em medicina preventiva e social pela UFF e mestre em Saúde Coletiva pelo IMS-UERJ. Endereço eletrônico: felipeolcav@yahoo.com.br. 


\section{Introdução}

Em outras oportunidades (GUIZARDI, 2009; GUIZARDI; CAVALCANTI, 2009; GUIZARDI 2008, GUIZARDI et al., 2006), procuramos discutir os processos de centralização normativa que têm caracterizado a implementação do Sistema Único de Saúde (SUS). Esta reflexão nos levou a problematizar o campo da gestão em saúde, o modo como atualiza práticas herdadas da tradição que tem orientado as estratégias de administração modernas, cuja emergência histórica é marcada por necessidades específicas do modo de produção que se configura a partir do final do século XIX com o desenvolvimento do capital monopolista.

No contexto histórico de emergência do campo da administração, o surgimento da gerência sinaliza, principalmente, a redução da autonomia dos trabalhadores sobre a tarefa, condição legitimada pela separação nas organizaçōes sociais entre o momento da concepção e o da execução das atividades de trabalho. Concordamos com a análise feita por Campos (2000), segundo a qual, não obstante seus compromissos democráticos, a efetivação do SUS seguiu os cânones dessa racionalidade gerencial hegemônica, marcada pelo exercício do controle e da disciplina.

Por outro lado, a experiência histórica de implementação do SUS manifestou a ineficácia resultante das tentativas de estabelecer objetivos, novos programas e instrumentos de produção de serviços, reorganizar os processos de trabalho em saúde, reformular a composição das equipes profissionais, construir novas unidades e disponibilizar verbas, inclusive grandes investimentos em capacitação profissional, sem que sejam questionadas no âmbito da gestão as relações cotidianas de poder que permeiam e configuram as instituições de saúde. De fato, um amplo leque de dificuldades enfrentadas nestes 21 anos de SUS, e que dizem respeito principalmente à estruturação do cotidiano das práticas de saúde no sentido da produção do cuidado, nos confronta com os limites das tentativas de reformar as instituições sem explicitar a dimensão política destas práticas, sem produzir visibilidade para as implicações que geram na produção de realidade social.

Tais questôes demonstram a necessidade de repensar os modos de gestão do sistema de saúde, já que o cotidiano institucional expõe as limitaçoos que a tradição gerencial enfrenta na concretização das políticas públicas que o estruturam, sobretudo quando se apresenta como horizonte desejado a transformação democrática de suas instituiçôes. A perspectiva de análise 
que adotamos se situa, portanto, nas relações institucionais e em seus efeitos,

pois concordamos com Campos (2000), em sua avaliação sobre a necessidade de democratização institucional e de produção de modos compartilhados de gestão. ${ }^{3}$ Desta forma, analisaremos neste trabalho o conceito de cogestão formulado pelo autor e discutiremos em seguida elementos que consideramos úteis à composição deste conceito.

\section{O conceito de cogestão e o problema da produção de democracia institucional nas Organizações Públicas de Saúde}

No livro "Um método para análise e cogestão de coletivos", em que propõe o Método da Roda (CAMPOS, 2000), Campos desenvolve uma reflexão teóricometodológica a partir das questôes anteriormente discutidas quanto à gestão, tomando a democratização institucional não apenas como um meio para efetivar mudanças sociais, mas "um fim em si mesmo". O autor parte de uma hipótese coerente com as composiçôes conceituais de seus trabalhos anteriores (CAMPOS, 1989, 1991, 1994, 1997), nos quais trouxe para o campo da administração em saúde a temática da produção de subjetividade. $\mathrm{O}$ objeto de sua discussão é a dupla função que a produção de valores de uso desempenha nas organizações: por um lado, cria bens ou serviços com potencial de garantir o atendimento de determinadas necessidades sociais e, por outro, atua na coprodução do sujeito e do coletivo organizado para esta produção.

Ao propor o objetivo de alterar o modo de gestão das instituições, o autor explicita a intenção de ampliar analiticamente o espaço da política e reconstruir seus modos de operação, indagando sobre a possibilidade das organizações sociais produzirem liberdade e autonomia ao invés de controle e dominação. Para isto, a ampliação do conceito de trabalho torna-se estratégica. Ele lança mão do recurso a novas fronteiras na delimitação de seus sentidos, procurando ultrapassar a acepção corriqueira de trabalho produtivo, definindo, então, o trabalho como toda atividade humana voltada para a produção de valores relevantes ao atendimento de necessidades sociais, o que inclui os esforços dirigidos à constituição dos sujeitos e à reconstrução das instituições. Em outras palavras, o emprego do tempo de trabalho na discussão coletiva e democrática sobre sua organização passa a ser compreendido como diretamente produtivo, 
na medida em que incide na maneira como se estruturam os processos de subjetivação. A produção do trabalho em saúde, portanto, é colocada para além da mera produção de consultas, procedimentos, etc.

Nessa direção, o conceito de cogestão é forjado por Campos (2000b) como articulador de um modelo de gestão que assume as premissas anteriormente expostas a respeito da democratização das instituições e da dupla função dos Coletivos Organizados para a Produção. O conceito é, portanto, uma resposta à clara implicação das teorias e práticas administrativas com processos de produção de alienação, de expropriação e restrição das esferas decisórias de governo, processos que resultam na indução ao agir burocrático e em condiçõos que consolidam uma perspectiva funcional de dominação. Em confronto com essa tradição, a cogestão apresenta-se como um projeto de construção de compromisso e solidariedade com o interesse público, de capacidade reflexiva e autonomia dos sujeitos. A partir da explicitação desses valores, o conceito afirma a dimensão coletiva da tarefa da gestão, que justamente por esta conformação não pode tornar-se atribuição de especialistas ou elites.

Assim, a cogestão teria uma dupla direção: por um lado, a construção de sentido para a ação e, por outro, a garantia das condições de sua concretização, dos meios materiais e subjetivos requeridos. Os objetos de investimento dos sujeitos e a satisfação de interesses e necessidades sociais seriam as finalidades polares a operarem as organizaçóes - ou seja, trata-se de incorporar o desejo dos trabalhadores na gestão dos processos de trabalho, sem que isto signifique desconsiderar o diálogo com as necessidades sociais.

No que tange aos meios organizacionais, o conceito de cogestão requisita uma configuração diferenciada da lógica que define as seções e departamentos na racionalidade gerencial hegemônica, estruturada em um eixo vertical e hierarquizado de poder, e outro que produz a fragmentação dos processos, dividindo os trabalhadores segundo especialidades e funçôes. Esquadrinhamento da organização que visa, sobretudo, à contenção de movimentos instituintes e à perpetuação da concentração de poder. Propõe-se como alternativa a noção de unidade de produção, que não seria desenhada segundo a lógica das especialidades ou corporações, mas reconhecendo como questão fundamental a produção de valores de uso e dos próprios coletivos de produção. Esta outra forma de organização representa uma tentativa de criar fluxos democráticos que 
provoquem transformações na rede de poder institucional, desde o organograma formal às relações entre unidades e pessoas.

A composição da equipe deve considerar a necessidade de compartilhar objetivos e objetos de trabalho, e ser orientada para a ampliação da capacidade de direção, por meio de relações horizontais, nas quais é garantido o acesso às questões e decisões cotidianas da organização. Em outras palavras, socializar "a habilidade e a potência para compor consensos, alianças e implementar projetos" (CAMPOS, 2000b, p. 43), as quais são recursos subjetivos que esgarçam a lógica da separação entre concepção e execução, atuando na aproximação entre governantes e governados e na formação de compromisso entre interesses públicos e privados.

Nessa medida, pode-se afirmar que a cogestão é um recurso de publicização das instituições, que tem como principal horizonte a construção de valores democráticos, de uma postura ética que atue como força de negação das estratégias de dominação e dos dispositivos de controle tão presentes nas práticas administrativas. $\mathrm{O}$ conceito aponta para o reconhecimento da possibilidade de instituir compromissos coletivos e para a necessidade de democratizar o poder em todas as dimensões da vida institucional e social: "a base da cogestão, ninguém governa sozinho" (CAMPOS, 2000b, p. 44). Estes aspectos tornam a proposta de cogestão apresentada por Campos um projeto político radicalmente antagônico à razão tecnocrática, e que se assenta na prática da "liberdade de se por em pauta os desejos e interesses dos trabalhadores" (CAMPOS, 2000b, p. 128).

Para o autor, a produção de uma nova sociabilidade democrática decorre do estabelecimento de compromissos entre os sujeitos, o que torna necessária a existência de uma dinâmica alternativa à conformada pela racionalidade gerencial, uma dinâmica que seja capaz de convocar e reforçar a participação não somente dos atores com função de direção. Este é, portanto, um tema fundamental à noção de cogestão: a constituição e os modos de operação dos espaços coletivos, definidos como arranjos de espaço-tempo concretos em que as equipes de trabalho podem interferir na organização da produção, ou seja, onde de fato o problema do poder seja publicamente colocado, a partir do engajamento na análise e deliberação coletivas. Os espaços coletivos são uma estratégia de democratização das relações de poder, de superação das capacidades assimétricas de decisão, que visa a garantir aos trabalhadores o acesso à informação e o tempo necessário aos processos de discussão, deliberação e planejamento. Nesses espaços, os sujeitos 
1250 devem ocupar-se do estabelecimento de compromissos quanto à tensão entre a produção de valores de uso e o interesse e desejo dos trabalhadores, uma vez que "a organização resulta da adesão mais ou menos voluntária a valores instituídos e transformados em estrutura, arranjos e normas" (CAMPOS, 2000b, p. 73).

Cogestão significa, então, compartilhamento de poder, constituição de uma rede em que os diferentes espaços convertem-se em instâncias de poder relativo, sujeitos a essas pressões, mas não inteiramente determinados por elas. Poderes parciais na medida em que é reconhecida e legitimada a exigência de considerar outros agrupamentos de interesse, outros projetos, coletivos e sujeitos. Desta forma, o conceito é particularmente fecundo por incidir diretamente na relação hierárquica que caracteriza historicamente a assistência à saúde, enfatizando a potencialidade produtiva e emancipatória da participação dos sujeitos, inclusive na definição das necessidades sociais a que os serviços, e em última instância, as políticas de saúde devem responder.

Há, entretanto, um ponto específico que pretendemos problematizar na formulação dada por Campos (2000) ao conceito de cogestão. Embora no livro Saúde Paideia (CAMPOS, 2005), essa ênfase seja suavizada, ainda assim, o modo como o autor propõe o conceito explicita que o compartilhamento da gestão se refere particularmente aos trabalhadores das organizações, sujeitos privilegiados dos espaços coletivos que se busca instituir. Compreensão que podemos evidenciar no enunciado de que "a gestão de Coletivos deve incorporar os usuários, mas não com o mesmo sentido e proporção que os trabalhadores" (CAMPOS, 2000, p. 72). Também podemos observar esta posição nas composiçôes propostas para conselhos gestores e colegiados. Nos primeiros, ao contrário dos trabalhadores, os usuários são inseridos mediante mecanismos representativos, sendo que não chegam a compor os segundos, tidos como espaços protegidos da equipe.

Nosso questionamento se dirige aos efeitos que podem derivar da diferenciação pretendida entre as implicações dos grupos sociais. Ao reconhecer maior pertinência à participação dos profissionais, o conceito de cogestão pode induzir, ou melhor, perpetuar, o modo como as instituições são apropriadas por usos corporativistas e privatistas, indo em direção contrária ao projeto de sua publicização e democratização. O próprio autor indica tal tendência, e propõe que as lideranças e os responsáveis pelo apoio institucional (que possuem 
atribuições específicas de gestão) tenham a tarefa de trazer para o cenário do trabalho interesses e perspectivas "externos".

Indagamos se a aposta na cogestão não deveria radicalizar-se, com o reconhecimento de todos na condição de sujeitos implicados com a produção das ações de saúde, o que não significa uma tentativa de homogeneização de seus saberes e responsabilidades. Ao contrário, é justamente a peculiaridade de suas diferentes inserções que importa quando defendida a participação ampliada como meio de democratização do cotidiano das instituiçôes. Na medida em que se limita à dinâmica interna das equipes de trabalho, consideramos que a formulação original não questiona suficientemente o funcionamento institucional, em sua capacidade de conter e fixar os fluxos sociais com sobrecodificações e hierarquias. Sinalizamos, com isso, a necessidade de ampliar o conceito de cogestão proposto por Campos, a fim de ultrapassar as práticas de organização do trabalho, em direção à articulação em rede das atividades de produção de saúde no território. Ainda que isto implique e afete o plano da organização do trabalho nas instituições de saúde, a cogestão não poderia ser nela delimitada, na medida em que requisita a diluição das fronteiras dessas instituiçóes. Com a perspectiva de desdobrar esse novo sentido do conceito, desenvolvemos nos tópicos seguintes elementos que podem contribuir com o debate sobre a democratização das instituições e políticas públicas de saúde.

\section{Fios e tramas para tecer o conceito de cogestão das instituições de saúde: a noção de porosidade}

$\mathrm{O}$ primeiro aspecto a abordar seria a noção de porosidade, que expressa a necessidade de desfazer a compactação uniforme dos muros institucionais, que delimitam o dentro e o fora dos serviços, abrindo canais de articulação dos processos de trabalho às redes sociais do território. Tratar-se-ia de uma desconstrução dos limites das unidades, das equipes e mesmo das tarefas e ações realizadas, que somente pode ser proporcionada pelo compromisso dialógico de definir de forma compartilhada os objetivos e estratégias de intervenção, seu valor, seu sentido. Este compromisso é necessariamente transversal, porque diz respeito não somente às atividades episódicas de planejamento (anuais, por exemplo), aos projetos intersetoriais, ou grupais, mas também se aplica à própria dinâmica da tradicional consulta individual, o que representa um desafio à racionalidade 
1252 biomédica que conforma a prática da grande maioria dos profissionais de saúde como relação hierarquizada e fechada em si mesma.

Esta noção traz para cena a necessidade de transformação reticular do trabalho em saúde, questão já apontada pelo conceito de espaço intercessor proposto por Emerson Merhy $(2005,2007)$. Para esse autor, o modo como os modelos tecnoassistenciais em saúde se concretizam cotidianamente nos serviços deve ser analisado a partir do emprego das tecnologias leves, particularmente do espaço de autogoverno que as caracterizam, e de suas formas de articulação e mobilização das demais tecnologias. Isto porque a especificidade do trabalho em saúde reside justamente na centralidade que o momento de encontro entre usuário e profissional possui. Diferentemente do trabalho fabril, em que a relação entre o consumidor e o processo produtivo depende da intermediação do objeto produzido, no setor de serviços essa separação não se efetiva com tal nitidez, já que o consumo acontece no mesmo momento da ação produtiva. A produção não pode ser entendida como prerrogativa exclusiva do profissional de saúde, cujo trabalho requer o estabelecimento da relação com o usuário. Portanto, a produção de intervenções em saúde é desenhada de modo particular pela presença das tecnologias leves na relação com o usuário final, no espaço intercessor que se conforma nesse encontro. Segundo Merhy (2005), tal espaço não pode ser analisado sem considerar sua configuração "quase estruturada", pois tanto usuários, como trabalhadores, instituem necessidades e atuam como forças na dinâmica de interseção entre produção e consumo.

A marcante presença das tecnologias leves no trabalho em saúde responde pela centralidade que o trabalho vivo em ato possui nesse processo, restringindo as possibilidades de sua captura na relação com o trabalho morto e na organização dos modos de gestão. Em outros termos, "a captura global do autogoverno nas práticas de saúde é impossível pela própria natureza tecnológica deste trabalho” (MERHY, 2007, p. 98). As escolhas em ato de que depende a produção em saúde, como condição para sua realização, conferem ao profissional um grau significativo de liberdade na conformação e concretização do trabalho.

O trabalho em saúde não pode ser globalmente capturado pela lógica do trabalho morto, expresso nos equipamentos e saberes tecnológicos estruturados, pois o seu objeto não é plenamente estruturado e suas tecnologias de ação mais estratégicas se configuram em processos de intervenção em ato, operando como tecnologias de relaçôes, de encontros de subjetividades, para além dos saberes tecnológicos estruturados (MERHY et al., 2007, p. 120). 
Na medida em que certas características do modelo assistencial baseado na racionalidade gerencial hegemônica permitem ao trabalhador de saúde responder exclusivamente pela liberdade que a dimensão pouco estruturada de seu processo de trabalho possui, coloca-se em consequência a possibilidade de privatização do uso desse espaço decisório. Se, por um lado, a autonomia do trabalho vivo em ato é ampla em relação aos movimentos de captura pelas tecnologias mais estruturadas de administração, por outro, também pode desvincular-se das necessidades de saúde da população. Em função destes aspectos, Merhy indica a importância que as tecnologias leves podem adquirir, quando tomadas como recurso de publicização do espaço de autonomia que caracteriza a atividade profissional em saúde. Pensar a gestão a partir desse desafio seria apostar nos atravessamentos que as distintas lógicas instituintes forjam; seria, no dizer do próprio autor, a abertura da "caixa preta" das tecnologias leves, a intervenção em processos capazes de promover alterações significativas no modo de se trabalhar em saúde (MERHY, 2007).

A tensa relação entre produção, consumo e necessidades de saúde faz com que o objeto de trabalho esteja sempre em estruturação, com grande imprecisão quanto aos padrões que qualificam os resultados pretendidos, especialmente quando o tema das necessidades é recolocado para além do julgo da carência e das normatizações biomédicas do que são corpo e vida saudáveis. Necessidades pensadas também como potência e desejo de ser, de constituir-se, o que não implica desconsiderar que são muitas vezes expressas ou ressignificadas pela influência exercida pelas tecnologias dos saberes estruturados.

Para o autor, tais imbricações, constitutivas da abertura permanente do trabalho à elaboração das necessidades de saúde, não permitem o julgamento peremptório da eficácia dos dispositivos tecnológicos, já que sua avaliação não concerne unicamente ao emprego e adequação do processo de trabalho em relação a certa racionalidade instrumental. Condiz, antes, às estratégias com que podemos interrogar as intencionalidades que gerem o trabalho vivo em ato, ao modo como opera essas dimensões tecnológicas, o diálogo que concretiza com expectativas e desejos apresentados pelos usuários e pelos próprios trabalhadores. Enfim, como atua o trabalho vivo em ato na invenção em processo destas necessidades, "no fazer que [...] se publiciza para uma nova validação ético-estética no campo do trabalho em saúde, portanto na intimidade entre o repensar a micropolítica do processo de 
trabalho em saúde e o seu processo de gestão"(MERHY, 2007, p. 111). Questão que consideramos atinente à construção da direcionalidade do trabalho em saúde, seu comprometimento com determinados valores - em suma, à sua dimensão política, na interface que exige e instaura com os processos de gestão.

Nesta perspectiva, produzir saúde em processos de cogestão requisita o exercício de capacidades normativas, inclusive no que tange à configuração institucional das alternativas de intervenção. Como indica o conceito elaborado por Campos (2000), reinventar as instituições de saúde significa reinventar nelas as formas de organização do trabalho, objetivo que confronta os sujeitos à necessidade de analisar e compartilhar as situações que enfrentam, construindo, em função delas, a corresponsabilidade com a formalização de compromissos coletivos.

As questões discutidas sobre a organização do trabalho indicam que o conceito de espaço intercessor pode ser útil ferramenta analítica ao desafio de produzir porosidade nas instituições de saúde, principalmente quando considerado em suas implicações reticulares, que se tecem dentro e fora dos espaços dos serviços de saúde. Nesse sentido, a perspectiva de associar a noção de espaço intercessor à produção de porosidade nas organizações de saúde pode ser remetida a dois desafios: o primeiro deles diz respeito à construção de mecanismos de publicização dos efeitos normativos das práticas institucionais; enquanto o segundo remete à integração em rede das estratégias mobilizadas e construídas nas intervenções. Esta integração, entre outros efeitos, poderia proporcionar um plano de visibilidade para a dimensão normativa das práticas de saúde (espaços de autogoverno, no dizer do autor), ao mesmo tempo em que pode oferecer suporte a sua concretização, ampliando o campo de interlocução e cooperação na resolução de impasses e dificuldades. Desta forma, produzir visibilidade para a dimensão normativa das ações em saúde significa tanto publicizar os modos de apropriação de normas e saberes que antecedem situações específicas, como também tornar pública a gestão das variabilidades inéditas que essas situações apresentam em sua historicidade. Esta concepção de cogestão demanda a construção de outras relações com a atividade de trabalho, pautadas na afirmação democrática de sua prerrogativa normativa, ou seja, na legitimidade de seu exercício por todos os implicados, ainda que isto não signifique de modo algum supor uma homogeneidade das formas de participação e responsabilização nas intervenções institucionais. 


\section{Democratização das instituições de saúde e produção de novas lógicas de pertencimento}

Intervir na gestão das instituições de saúde nos demanda reconhecer sua capacidade produtiva de relações, de constituição de referências que apresentam uma temporalidade de permanência. Trata-se do reconhecimento de um dos principais aspectos que responde diretamente pelo engajamento dos sujeitos em movimentos de atualização de práticas e sentidos. Falamos aqui da noção de pertencimento, dos efeitos de subjetivação que gera e dos campos de possibilidade que podem ser explorados a partir dela.

Tradicionalmente, o vínculo, o sentimento de pertencer às instituições, é mobilizado como desejo de participar do que nos parece ser um movimento circular, de reconhecimento identitário, que se fecha em um circuito estrito, no qual são delimitadas determinadas referências de identidade, que não se revelam disponíveis para processos capazes de produzir diferenciação. $\mathrm{O}$ principal efeito deste circuito identitário é a conformação de um dentro e um fora das instituições, estabelecendo uma fronteira que legitima o direito (ou não) à participação nas decisões institucionais. Em grande medida, esse processo responde pela capacidade que as instituições têm de conferir durabilidade e constância aos processos sociais, mas a questão que se nos coloca com tal observação deve ser buscada além destes efeitos, como uma interrogação sobre as condições de eficácia desses agenciamentos de desejo.

Levantamos aqui uma hipótese explicativa simples, a de que tal poder de vinculação expressa, sobretudo, nossa condição de seres de relação, a impossibilidade do viver humano de acontecer em isolamento. Necessitamos do outro como condição de nosso próprio reconhecimento, imperativo dialógico ao qual respondem as práticas institucionais e do qual decorre sua eficácia política. Aliás, não é aleatório que o imenso potencial de novas e outras relaçóes, oportunizado pelas tecnologias de comunicação e informação contemporâneas, que desfazem diversas ordens de fronteiras (sociais, culturais, linguísticas, espaciais e temporais), tenha sido acompanhado de uma intensificação exacerbada da produção de fragmentação e isolamento social como tecnologia de governo dessa "monstruosidade", por definiçãao ingovernável, que se afirma e produz no encontro das singularidades. É preciso que estejamos conectados para os processos de valorização do capital e 
desconectados para o fora, o virtual que põe em xeque, a todo instante, essa própria restrição. Tais tecnologias de governo que procuram impedir o exercício franco da liberdade de que nos fala Arendt (1998), liberdade política de produção do novo, de articulação de novos territórios existenciais, da criação de outros modos de valoração e significação da experiência humana.

A produção do medo em nossas cidades, a vida que se percebe sitiada, a construção do outro como ameaça, todos esses artifícios coincidem com a atual e potencial ampliação indeterminada das redes, a qual nos mostra a potência constituinte dessas relações de vinculação. Este aspecto tem sido sinalizado no campo da saúde por autores do modelo em defesa da vida (CAMPOS, 1989, 1991, 1994, 1997, 2000, 2005; MERHY, 1997, 2005), ao apostarem no vínculo como estratégia primordial de transformação das práticas sanitárias e do modelo assistencial que as orienta.

O que pretendemos aqui explorar é justamente uma apropriação constituinte dos espaços institucionais, que invista em relaçóes éticas de pertencimento (valores e sentidos compartilhados para a produção de saúde), e não em atualização de hierarquias e exclusóes, delimitadas pelos muros das instituiçóes. Por isso, uma perspectiva de instituição porosa, que se exponha e se confunda com os processos produtivos do território, tornando-se eficaz também em inventar nessa aproximação relações éticas de pertencimento. A referência à ética é aqui significada como reconhecimento do outro em sua diferença, sem o que não conseguiremos concretizar as malhas institucionais dos serviços de saúde como espaço de pertencimento solidário.

A noção de pertencimento apresentada confronta-se, portanto, com a lógica tradicional da produção de vínculos institucionais, que se efetiva como identidade, como estabelecimento de fronteiras deste reconhecimento de legitimidade, em função das quais as instituições pretendem reportar-se apenas aos iguais, quando situam com seus muros simbólicos a diferença como externalidade. Este é um efeito que pode ser averiguado como transversal às tecnologias de governo em que se fundam as instituições, dadas as estratificações e hierarquias que as caracterizam, o que nos ajuda a compreender a dificuldade que vivenciamos em tornar os serviços de saúde espaços públicos, nos quais os usuários se reconheçam e sejam reconhecidos como sujeitos de relação, e não objeto de intervenção (ainda quando gentilmente tratados). 
A perspectiva de uma instituição porosa, produzida por meio de redes sociais mais amplas, requer a construção de dispositivos de encontro e de experiência da alteridade, que desmistifiquem o outro como ameaça a uma posição identitária. A preocupação com este aspecto se deve porque todos nós circulamos por diversos territórios subjetivos, somos vários nesse sentido, e o reconhecimento disto é fundamental a uma implicação ética com a produção de saúde. Nesse sentido, a alteridade remete, diretamente, à circulação de afetos, à disponibilidade com que nos colocamos em relação ao outro, pois, como indica Lazzarato (2006, p. 33), "diferença é sentir, pathos", não pode ser reduzida ao registro da cognição, do direito formal, das obrigaçôes profissionais, pois "agir significa modificar a maneira de sentir junto [...]. Criar e efetuar mundos significa agir sobre crenças e sobre os desejos, sobre as vontades e inteligências, ou seja, agir sobre os afetos" (LAZZARATO, 2006, p. 32).

Nossa proposição é que as malhas institucionais dos serviços de saúde poderiam gerar o sentimento de pertença ao integrar singularidades em relações de vizinhança, de proximidade. Não uma reunião assentada em unificações funcionais, generalizações ou categorias abstratas, enfim, em qualquer modo de totalização, mas a convergência de pequenas diferenças, a integração das infinitesimais variações que compõem o social.

Pertencimento tem aqui o sentido de reconhecimento e integração, experiência de afecção, de sentir o outro em sua diferença como alguém com quem se compartilha o direito ao bem-Comum. Não se trata, contudo, da adesão a mundos ofertados pela produção midiática, que busca acoplar-se e direcionar os investimentos de desejo da população, oferecendo maneiras de sentir e de viver numa criação autoritária de sentido. Ao contrário, buscamos compreender o pertencimento como uma forma de vinculação solidária na construção política de territórios existenciais, ou seja, falamos de uma intencionalidade política que procura incidir diretamente na produção de pertencimento agenciada pelo consumo como adesão a certo universo de valores estabelecidos nas fronteiras das relações de Capital.

\section{Conhecimento e cogestão}

Em sua preocupação em analisar as possibilidades comunicativas do planejamento em saúde, Rivera (1996) sinaliza uma questão importante quando coloca em discussão a interação comunicativa e a coordenação lateral 
nas organizações, advogando que a configuração institucional deve adaptar-se à rede de produção, aos seus fluxos e aos modos de realização dos processos e das conversações. Discordamos, por um lado, dos limites de sua análise, que se revelam referidos à cultura organizacional. Por outro lado, essas sinalizações nos parecem apropriadas, principalmente por estarem assentadas na constatação de que a transformação da gestão é antes uma questão de criação de valores que de processos técnicos, implicando "a maior incorporação possível de práticas de gestão pelo maior número de atores” (RIVERA, 1996, p. 366). Neste ponto, o autor indica a necessidade de socialização da gestão, ressaltando a importância de horizontalizar os processos institucionais, o que em nossa discussão pode ser trabalhado desde a perspectiva de dispersão destes processos como redes sóciotécnicas de produção de saúde.

Este objetivo, coerente com a noção de cogestão que defendemos, interpela diretamente o problema do conhecimento e de sua circulação, pois este é o principal recurso de estratificação das relações, de legitimidade que determina quem está, ou não, apto a intervir nos processos institucionais. Falamos especificamente do conhecimento científico, é preciso esclarecer, que na modernidade assumiu o papel primordial da tradição, da autoridade, no sentido que lhe confere Hanna Arendt (2005). Segundo a autora, a autoridade deve ser entendida como responsável pela exigência de obediência, não é nem força, nem violência direta, mas o poder de submeter sem o recurso a meios externos de coerção. Assim, a relação de autoridade é uma relação necessariamente hierárquica, que exclui qualquer modo de persuasão ou argumentação, já que nela se reconhece anteriormente a divisão entre quem manda e quem obedece, assentada na legitimidade e no direito que a própria autoridade confere, e a partir do qual se estabelecem os lugares pré-definidos da relação.

Se olharmos as relações entre os conhecimentos científicos e as instituições disciplinares com as lentes deste conceito, parece quase evidente sua adequação analítica, muito embora não se possa desconsiderar toda a mobilização do corpo (e de sua memória física) feita pela disciplina, como violência silenciosa (ou nem tanto). De qualquer modo, o conceito de autoridade mostra-se útil na compreensão das relações produzidas no âmbito institucional, com suas prerrogativas hierárquicas, eficazes em estabelecer lugares específicos, que são diferenciados pela legitimidade que o conhecimento científico aufere a seus porta-vozes. O conceito de autoridade 
é útil na medida em que nos expõe a conexão íntima entre conhecimento e legitimidade, ponto crucial a ser problematizado quando propomos engendrar outras configuraçooes institucionais, que sejam capazes de viabilizar a cogestão como compromisso de criação do novo, a partir da democratização do exercício normativo e da flexibilidade técnico-política de seus processos.

Ao discutir as interseções entre ciência e política Gonçalves, Schraiber e Nemes (1990) indicam a impossibilidade de dissociar a produção de conhecimento das relaçôes sociais, a cidade científica, suas regras e valores, da cidade social e historicamente determinada dos homens. Conhecimento e política não poderiam separar-se quando está em jogo a construção permanente da democracia, a materialização de alternativas e experimentações sociais que respondam ao desafio de produzir o SUS como um bem-comum.

Não se trata, então, de negar o conhecimento como condição da produção de valores, mas de desfazer as lógicas hierárquicas implícitas na relação entre conhecimento científico e os demais saberes, as quais não precisam sequer ser enunciadas, já que vividas como autoridade natural em sua capacidade de preestabelecer os campos de possibilidade das práticas institucionais. $\mathrm{O}$ estranhamento desta posição de autoridade é condição fundamental para a cooperação na produção de saúde poder requisitar e estabelecer-se nas redes sociais. Isto, entretanto, não deve ser confundido somente com o acesso ampliado à informação (o que frequentemente mantém a exclusividade normativa do conhecimento científico), mas como socialização de sua própria construção, sobretudo se entendemos o conhecimento a partir da acepção compartilhada por Nietzsche e Tarde, como o afeto mais importante, pois faz convergir a dimensão judicial e intelectual da subjetividade (LAZZARATO, 2001).

A potência produtiva que dispõem os conhecimentos baseia-se em suas características: são inteligíveis, inapropriáveis, não-cambiáveis e inconsumíveis (LAZZARATO, 2003). Eles não se conformam à lógica da apropriação privada da riqueza, pois as trocas que permitem não podem ser efetuadas segundo o critério da acumulação, da expropriação e da destruição. Ao ofertar um conhecimento, o sujeito que o concede dele não se despoja, não o perde; ao contrário, o valor que adquire depende da extensão com que é partilhado e difundido. Os conhecimentos são, assim, bens que resistem em ser divididos e alienados em razão da troca econômica; seu consumo não é predatório, mas criador, já que pode imediatamente gerar um 
novo processo de inovação. Nesse sentido, os conhecimentos são resultado essencial da cooperação pública, já que dependem do universo de saberes compartilhados e de suas interlocuções dialógicas.

A centralidade que os conhecimentos adquirem nos novos modos de produção (CORSANI, 2003) nos reporta alguns aspectos que não devem ser desconsiderados, quando pensamos nas possíveis explicações para a eficácia do conhecimento científico, que não é somente derivada de uma posição de autoridade, o que nos traz o desafio de entrever do que advém sua legitimidade e sua capacidade de mobilização produtiva. Quanto a isto, dois fatores nos parecem preponderantes: a interseção entre sua dinâmica reticular e a capacidade de sistematização e articulação que o compartilhamento de regras e a explicitação dos percursos de sua construção torna possível. Essas características nos permitem vislumbrar o motivo por que a internet, exemplo emblemático do potencial de cooperação produtiva das redes (de redes), tenha surgido justamente no âmbito das trocas acadêmicas, quando o consumo passivo de informaçôes possibilitado pelas redes informáticas foi sendo substituído por um processo de criatividade interativa (BARBROOK, 2003).

Essas seriam dimensões aparentemente paradoxais do saber científico, que por um lado é fruto da "cooperação horizontal" e da publicização de seus caminhos de construção e, por outro, fundamenta processos institucionais de exclusão e hierarquização. Talvez possamos compreender essa contradição como uma recomposição das tecnologias de comando, derivada justamente das possibilidades de democratização gerada pela circulação e sistematização dos saberes.

Ao aproximar a produção de conhecimento e a troca de saberes do conceito de cogestão, procuramos resgatar os efeitos formativos das redes institucionais na produção de territórios existenciais, de processos de subjetivação. O que queremos apontar é a necessidade de inserir na composição institucional dos dispositivos de cogestão a produção de saberes como efeito de trocas nãohierárquicas, que demandam tanto um grau diferenciado de publicização (em relação aos saberes tácitos), como uma dinâmica reticular de apropriação, compartilhamento e sistematização.

Nesse sentido, a articulação de dispositivos de cogestão está estreitamente condicionada pelas possibilidades de apropriação e produção de informações e conhecimentos, o que demanda novas estratégias e dispositivos de expressão, 
aprendizagem, sistematização e comunicação da experiência de produção de saúde, não restritas aos mecanismos de representação e aos universos técnico-científicos do campo. Podemos, então, pensar na "coordenação e desenvolvimento das aprendizagens coletivas, de expertises coletivas que fazem emergir os 'objetos' e os ‘sujeitos' políticos” (LAZZARATO, 2006, p. 225) como decorrente da publicização e articulação reticular da dimensão normativa das práticas de saúde (que extrapola os espaços de autogoverno dos profissionais). Em suma, um aprendizado compartilhado sobre suas implicações éticas e seus efeitos de realidade.

\section{Considerações provisórias sobre o conceito de cogestão}

Ao remetermos o conceito de cogestão para o plano da articulação em rede das atividades de produção de saúde, procuramos refletir sobre o desafio de construção de novas sociabilidades democráticas, capazes de concretizar materialmente o direito à saúde. Nesse sentido, entendemos que a gestão das instituições de saúde é responsabilidade ética de todos, pois a realidade (institucional) é necessariamente uma produção compartilhada.

Pensar em novos modos de gestão compartilhada demanda desfazer as fronteiras institucionais, suas hierarquias e processos de desqualificação e exclusão, e investir no território diretamente como campo de produção de saúde, considerando que ele, inclusive, independe das instituições formalmente tidas como "de saúde" para sê-lo. Falamos, portanto, de um esforço de aproximação que nos permita concretizar novas articulações institucionais que não atualizem a intervenção em saúde como uma reprodução de normalizações sobrecodificadas e heterodeterminadas. Essas questôes expressam uma compreensão da cogestão como socialização e democratização da constituição de artifícios institucionais, e o reconhecimento de sua dependência direta dos fluxos e redes sociais que promovem a socialização dos saberes, dos dispositivos tecnológicos e organizativos.

A cogestão das instituições seria, nessa perspectiva, a outra face da coprodução de saúde, vinculação que explicitamos por realocar a descentralização do sistema de saúde no horizonte da efetiva apropriação democrática dos processos de sua gestão. Estas transformações administrativas dos serviços de saúde dependem da exposição dos espaços institucionais à multiplicidade normativa dos fluxos 
societários e de suas composições singulares, o que implica a ruptura da tendência de centralização e concentração do poder normativo da gestão que tem caracterizado a implementação do SUS. Frente a esses desafios, podemos rever um vasto leque de obstáculos presentes no processo da construção da política de saúde, o qual se explicita na dificuldade de articular desenhos institucionais adequados às especificidades locorregionais. Tal conjunto de dificuldades tem apresentado constrangimentos para concretização do SUS como território público, como plano de visibilidade que torne acessível a seus sujeitos a dimensão política das práticas de saúde, ao mesmo passo em que se efetua como contexto de expressão e materialização de sua diversidade e singularidades na produção de saúde.

\section{Referências}

AGAMBEN, G. O que é um dispositivo. Outra travessia: revista de literatura. Ilha de Santa Catarina, n. 5, p. 9-16, 2005.

ARENDT, H. Entre o passado e futuro. São Paulo: Perspectiva, 2005. 348p. O que é a politica. Rio de Janeiro: Bertrand Brasil, 1998. 240p.

BARBROOK, R. A regulamentação da liberdade: liberdade de expressão, liberdade de comércio e liberdade de dádiva na rede. In: COCCO, G.; GALVÃO, A.P.; SILVA, G. Capitalismo cognitivo: trabalho, redes e inovação. Rio de Janeiro: DP\&A Ed., 2003. p. 61-82.

CAMPOS, G.W.S. Considerações sobre o processo de administração e gerência de serviços de saúde. In: CAMPOS, G.W.S.; MERHY, E.E.; NUNES, E.D. Planejamento sem normas. São Paulo: Hucitec, 1989. p. 9-32. . A saúde pública e a defesa da vida. São Paulo: Hucitec, 1991, 175 p.

Considerações sobre a arte e a ciência da mudança: revolução das coisas e reforma das pessoas. In: CECILIO, L.C.O. (Org.). Inventando a mudança na saúde. São Paulo: Hucitec, 1994. p. 29-88.

Subjetividade e administração de pessoal: considerações sobre a gestão do trabalho em equipes de saúde. In: MERHY, E.E.; CECÍlIO, L.C.O.; ONOCKO, R. (Org.). Agir em saúde: um desafio para o público. $1^{\text {a }}$ ed. São Paulo: Hucitec, 1997, p. 229-266.

- Um método para análise e cogestão de coletivos. A constituição do sujeito a produção de valor de uso e a democracia em instituições: o método da roda. São Paulo: Hucitec, 2000. 236p.

Saúde Paideia. São Paulo: Hucitec, 2005. 185p.

. Reflexões sobre o Sistema Único de Saúde: inovaçōes e limites. Revista do Serviço Público, v.esp., Brasília, p. 123-132, 2007. 
CORSANI, A. Elementos de uma ruptura: a hipótese do capitalismo cognitivo. In: COC-

CO, G.; GALVÃO, A.P.; SILVA, G. Capitalismo cognitivo: trabalho, redes e inovação. Rio de Janeiro: DP\&A, 2003. p. 15-32.

DELEUZE, G.; GUATTARI, F. Mil platôs: capitalismo e esquisofrenia. V. 1. São Paulo: Editora 34, 1995. 93p.

FRANCO, A.; POGREBINSCHI, T. (Org.). Democracia cooperativa. Escritos políticos escolhidos de John Dewey. Porto Alegre: EdPUC-RS, 2008. 152p.

GONÇALVES, R.B.M.; SCHRAIBER, L.B.; NEMES, M.I.B. Seis teses sobre a ação programática em saúde. In: SCHRAIBER, L.B. (Org.). Programação em saúde hoje. São Paulo: Hucitec, 1990. p. 37-63.

GUIZARDI, F.L. Do controle social à gestão participativa: interrogações sobre a participação política no SUS. Trabalho, educação e saúde (Online), v. 7, p. 9-34, 2009.

- Do controle social à gestão participativa: perspectivas pós-soberanas para a participação política no SUS . 2008. 259 p. Tese (Doutorado em Saúde Coletiva) - Instituto de Medicina Social, Universidade do Estado do Rio de Janeiro, Rio de Janeiro, 2008.

GUIZARDI, F. L.; CAVALCANTI, F.O.L. Por um mundo democrático produzido democraticamente (ou: o desafio da produção do comum): contribuições a partir da experiência do Sistema Único Brasileiro. Lugar Comum. Rio de Janeiro, n. 27, p. 103-123, 2009.

GUIZARDI, F.L.; PINHEIRO, R. Participação política e cotidiano da gestão em saúde: um ensaio sobre a potencialidade formativa das relações institucionais. In: PINHEIRO, R.; MATTOS, R.A. (Org.). Gestão em redes: práticas de avaliação, formação e participação na saúde. Rio de Janeiro: Cepesc, 2006. p. 369-384.

HARDT, M. Thomas Jefferson ou a transição da democracia. Lugar Comum, Rio de Janeiro, n. 27, p. 11-28, 2009.

LAZZARATO, M. As revoluçôes do capitalismo. Rio de Janeiro: Civilização Brasileira, 2006. 268p.

O ciclo da produção imaterial. In: LAZZARATO, M.; NEGRI, A. Trabalho imaterial. Rio de Janeiro: DP\&A Ed., 2001. p. 43-54.

- Trabalho e capital na produção dos conhecimentos: uma leitura através da obra de Gabriel Tarde. In: COCCO, G.; GALVÃO, A.P.; SILVA, G. Capitalismo cognitivo: trabalho, redes e inovação. Rio de Janeiro: DP\&A, 2003. p. 61-82.

MERHY, E.E. Saúde: a cartografia do trabalho vivo. São Paulo: Hucitec, 2005. 189p.

. Em busca do tempo perdido: a micropolítica do trabalho vivo em saúde. In:

MERHY, E.; ONOCKO, R. (Org.). Agir em saúde: um desafio para o público. São Paulo: Hucitec, 2007. p. 71-112.

RIVERA, F.J.U. A gestão situacional (em saúde) e a organização comunicante. Cad. Saúde Pública. Rio de Janeiro, v. 12, n. 3, 357-372, 1996. 


\section{Notas}

${ }^{1} \mathrm{O}$ conceito de democracia utilizado no âmbito deste trabalho coaduna com a maneira como o mesmo é trabalhado por atores como Hardt (2009) e Dewey (apud FRANCO; POGREBINSCHI, 2008), isto é, diz respeito não meramente ao que se convencionou denominar por democracia liberal, ou seja, a instituição de mecanismos formais a reger o sistema político (alternância no poder, pesos e contrapesos, liberdade de expressão, etc.), mas diz respeito ampliação da participação nas decisões que incidem na maneira como se constrói a vida coletiva a partir de arranjos que ultrapassem a democracia representativa. Neste texto, esta acepção é particularmente importante no que diz respeito à gestão das instituições, frisando a necessidade de que as mesmas sejam geridas não apenas pelos atores que ocupam lugares formais de decisão, mas por todos os indivíduos e coletivos direta ou indiretamente afetos a elas.

${ }^{2}$ A noção de subjetividade que percorre este texto é influenciada pela esquizo-análise, particularmente os autores Deleuze e Guattari (1995). A subjetividade, os sujeitos são compreendidos como mutáveis no tempo e no espaço, múltiplos, formando-se e transformando-se continuamente nos processos de subjetivação por que são atravessados ao longo de suas vidas. Desse elemento deriva a utilização no texto da expressão "produção de subjetividade" de maneira a frisar seu caráter de permanente mutação.

${ }^{3}$ As tecnologias leves na perspectiva do autor concernem os processos relacionais e subjetivos, como o vínculo e o acolhimento. Apesar de pouco estruturadas, comandam os processos cotidianos de configuração tecnológica na medida em que são o momento de definição da incorporação de outras tecnologias.

${ }^{4}$ Adotamos o conceito de dispositivo em uma acepção foucaltiana, segundo a qual este conceito remete às redes que se delineiam entre elementos heterogêneos (leis, medidas administrativas e de segurança, enunciados científicos, componentes de discursos, instituiçóes etc.), conformando certa 'disposição' destes elementos que se revela por si mesma produtora de efeitos (AGAMBEN, 2005). 
The concept of co-management of health institutions: reflections on the production of institutional democracy

This essay aims to discuss the necessary elements to build the concept of co-management from the perspective of the need to rethink ways of managing the Unified Health System, once the institutional routine exposes the limitations that traditional management faces to implement public policies, especially when it is a goal for the democratic transformation of their institutions. We present the concept of co-management formulated by Campos, and then perform a theoretical examination of three specific elements, namely: the concept of porosity, the production of new institutional logics of belonging and the relationship between co-management and knowledge. Finally, we propose that co-management be considered as the socialization and democratization of institutional devices, highlighting the its dependence on flows and social networks that promote the socialization of knowledge, of organizational and technological devices. By referring the concept of co-management to networking activities of health production we seek to reflect on the challenge of building a new democratic sociability, able to materialize the right to health. The comanagement of institutions would be, in this perspective, fundamental for the co-production of health.

Key words: health management, democracy, public policy. 